\title{
INTEGRAÇÃO DE AÇÕES NA GESTÃ̃ SUSTENTÁVEL
}

\author{
José Roberto Ribas* \\ jroberto_ribas@hotmail.com \\ Túlio Vagner dos Santos Vicente** \\ tuliovagner@yahoo.com.br \\ Joyce GonçalvesAltaf*** \\ jgaltaf@yahoo.com.br \\ Irene RaguenetTroccoli**** \\ irene.troccoli@estacio.br \\ * Universidade Federal do Rio de Janeiro \\ ** Instituto Estadual do Ambiente \\ *** Fundação Educacional Machado Sobrinho \\ **** Universidade Estácio de Sá
}

http://dx.doi.org/10.1590/1413.2311.112.58086

Recebido em 26/08/2015

Aprovado em 22/06/2017

Disponibilizado em 07/08/2017

Avaliado pelo sistema "doubleblindreview"

Revista Eletrônica de Administração

Editoras-chefe: Andrea Oltramari e Maria Ceci Misoczky

ISSN 1413-2311 (versão“online")

Editada pela Escola de Administração da Universidade Federal do Rio Grande do Sul

Periodicidade: Quadrimestral

Sistema requerido: Adobe Acrobat Reader

\section{RESUMO}

A sociedade, afetada pelas desigualdades, pela pobreza e pela fome, dentre outras mazelas, forma um quadro que não pode mais ser desconsiderado pelas organizações. As ações por proteção ambiental e justiça social podem se articular na medida em que esses contextos se completam e têm em comum um objetivo final. As empresas evitam investir em tratamento e em incineração de resíduos, uma vez que podem descartá-los em áreas desvalorizadas, abandonadas pelos investimentos públicos em infraestrutura urbana, e habitadas por populações pobres e menos organizadas. O presente artigo objetiva identificar e classificar as ações que se inter-relacionam e que descrevem três planos interdependentes apoiados na educação socioambiental - responsabilidade social corporativa (RSC), gestão ambiental e Marketing ambiental - dentro de uma estrutura de referência cujos elementos buscam identificar o compromisso empresarial com a questão socioambiental, aqui denominada Gestão Sustentável Integrada (GSI). A identificação das ações representativas em cada face ocorreu com abordagem exploratória com consulta a dados secundários, extraídos principalmente das publicações do Instituto Ethos, e das normas brasileiras (NBR) ISO 14.001 e ISO 14.004. Consulta envolvendo 15 especialistas em meio ambiente originou a 
classificação ordinal das ações relevantes para cada face da GSI, tendo-se concluído que: 1) as ações de responsabilidade social estão vinculadas primordialmente à transparência na gestão; 2) na gestão ambiental, significa racionalizar produtos, processos e serviços da empresa; 3) o Marketing ambiental deve se concentrar na seleção de fornecedores, concepção de projetos e de inovações que mitiguem o impacto ambiental.

Palavras-chave: Responsabilidade Social. Gestão Ambiental.Marketing Ambiental.

\begin{abstract}
Inequality, poverty and hunger affect societies andcan no longer be overlooked by organizations. Actions for environmental protection and social justice can be put together since they are complementary and have a common ultimate goal. Companies avoid investing in treatment and waste incineration, as they may discard them in devalued areas, with low public investment in urban infrastructure and inhabited by poor and less organized citizens. This article presents a frame of reference that refers tosocio-environmental corporate responsibility, here called Integrated Sustainable Management - GSI. It is formed by three independent elements: corporate social responsibility, environmental administration and environmental marketing, all based on socio-environmental education. Through an exploratory approach, the salient actions of each element are identified, through secondary data mainly obtained in publications of Instituto Ethos and in Brazilian norms (NBR) ISO 14.001 and ISO 14.004. A total of 15 environment specialists were consulted, from which an ordinal classification of the relevant actions in each element of GSI was obtained, having been concluded that: 1) social responsibility motions are primarily linked to managerial transparency; 2) in what concerns environmental management, it means rationalizing products, processes and services in the company; 3) environmental marketing must focus on the selection of suppliers, on the conception of projects and on innovations that minimize environmental impact.
\end{abstract}

Key-words: Social Responsibility. Environmental Administration.Environmental Marketing.

\title{
RESUMEN
}

La sociedad, afectada por la desigualdad, la pobreza y el hambre, entre otros males, forma un marco de trabajo que ya no puede ser pasada por alto por las organizaciones. Acciones para la protección del medio ambiente y la justicia social se pueden articular en la medida en que estos contextos son complementarios y tienen un objetivo final común. Las empresas evitan invertir en el tratamiento y la incineración de residuos, ya que pueden desprenderse de ellos en zonas devaluados, abandonado por la inversión pública en infraestructura urbana y habitada por poblaciones pobres y menos organizadas. Este artículo presenta un marco de referencia que se refiere a la responsabilidad corporativa socio-ambiental, aquí llamado Integró Gestión Sostenible - GSI. Es formado por tres elementos independientes: responsabilidad social corporativa, la administración ambiental y el marketing ambiental, todo basado en la educación socio-ambiental. Por un enfoque exploratorio, las acciones notables de cada elemento son identificadas, por datos secundarios obtuvieron principalmente en publicaciones de Genio de Instituto y en normas brasileñas (NBR) ISO 14,001 e ISO 14,004. Un suma de 15 especialistas de ambiente fue consultado, de que una clasificación ordinal de 
las acciones pertinentes en cada elemento de GSI fue obtenida, concluida eso: 1) movimientos sociales de responsabilidad son ligados principalmente a la transparencia directiva; 2) en lo que concierne gestión ambiental, significa productos que racionalizan, los procesos y los servicios en la compañía; 3) el marketing ambiental debe centrarse en la selección de suministradores, en la concepción de proyectos y en las innovaciones que minimizan impacto ambiental.

Palabras-clave: Responsabilidad Social. Administración Ambiental. Marketing Ambiental.

\section{INTRODUÇÃO}

A síntese do relatório do Painel Intergovernamental sobre Mudanças Climáticas ${ }^{\mathrm{i}}$ (IPCC, 2007) confirmou que as alterações do clima no mundo - incluindo o aquecimento global - são, provavelmente, causadas pela ação humana desde o começo da era industrial, principalmente a relacionada às emissões de dióxido de carbono.

Segundo o relatório, a temperatura aumentará 0,2 graus por década devido aos gases do efeito estufa acumulados. A utilização de combustíveis fósseis está entre as principais fontes geradoras de dióxido de carbono, bem como as queimadas de florestas e de resíduos. Todas essas ações são desencadeadas, direta ou indiretamente, por organizações que atualmente fazem parte do problema, sendo necessário que, futuramente, passem a fazer parte da solução.

Diversos encontros e documentos têm evidenciado esta problemática, tais como: (1) a Agenda $21^{\mathrm{ii}}$, que indica que os países devem estabelecer programas voltados ao exame dos padrões insustentáveis de produção e de consumo, e ao desenvolvimento de políticas e de estratégias nacionais de estímulo a mudanças nos padrões insustentáveis de consumo; (2) a Declaração do Rio iii, que indica que os Estados devem reduzir e eliminar padrões insustentáveis de produção e de consumo, e promover políticas demográficas adequadas (ONU, 2001); e (3) a Declaração de Johannesburgo ${ }^{\text {iv }}$, que estabelece a adoção do consumo sustentável como princípio basilar do desenvolvimento sustentável (MMA, 2008).

A sociedade, afetada pelas desigualdades, pela pobreza e pela fome, dentre outras mazelas, forma um quadro que não pode mais ser desconsiderado pelas organizações. As ações por proteção ambiental e por justiça social podem se articular na medida em que esses contextos se completam e que têm em comum um objetivo final. Acselrad (2005) afirmou ser a desigualdade ambiental fruto da desigualdade social, fazendo com que a moradia em local de risco seja a solução de habitação para a pessoa com baixo poder aquisitivo. Esse mesmo autor argumenta que ocorre descaso das empresas para com os problemas ambientais, bem como omissão das políticas públicas, que acabam por permitir a ação perversa do mercado.

REAd | Porto Alegre - Edição 86 - No 2 - Maio / Agosto 2017 - p. 31 - 57 
Dessa maneira, as empresas evitam investir em tratamento e em incineração de resíduos, uma vez que podem descartá-los em áreas desvalorizadas, abandonadas pelos investimentos públicos em infraestrutura urbana, e habitadas por populações pobres e menos organizadas.

Aparentemente, os maiores esforços corporativos na melhoria da imagem ou da reputação não estão alinhados com as reais carências ambientais. Nesse aspecto, percebe-se que o vínculo entre a responsabilidade social corporativa e o Marketing ambiental ocorre no aspecto da diferenciação de produtos. Assim, o Marketing vertical explora a preferência do consumidor entre produtos comparáveis, valorizando a agregação de valores que possuam atributos ecológicos, a exemplo da eficiência no consumo de energia (McWILLIAMS; SIEGEL; WRIGHT, 2006).

As abordagens que tratam da articulação entre a responsabilidade social e o meio ambiente enfatizam, principalmente:o papel que as empresas do setor privado representam na mudança de hábitos em direção a atitudes sustentáveis (JENKINS; YAKOVLEVA, 2006; KATSIKEAS; LEONIDOU; ZERITI, 2016); o resultado econômico que tais ações representam no balanço corporativo (BURKE; LOGSDON, 1996; DIXON-FOWLER et al., 2013;FLAMMER, 2015; AHI; SEARCY, 2015; LEONIDOU et al., 2015); as competências internas e a cultura empresarial (LEONIDOU et al., 2015); e o desenvolvimento dos fornecedores e a cadeia de suprimentos (PAULRAJ; CHEN; BLOME, 2015; AĞAN et al., 2016).

Em sua maioria, as pesquisas não estabelecem, com a devida transparência, sobre a importância em se adotar um procedimento metodológico que estabeleça uma abordagem conjunta das dimensões sociais, ambientais e econômicas.

Por isso,o presente artigo se propõe a preencher uma lacuna na investigação sobre sustentabilidade, já que seu objetivo éidentificar e classificar as ações que se inter-relacionam e que descrevem três conceitos - responsabilidade social corporativa (RSC), gestão ambiental e Marketing ambiental - dentro de esquema denominado Gestão Sustentável Integrada (GSI).

\section{A GESTÃO SUSTENTÁVEL INTEGRADA (GSI)}

Por definição da Comissão Mundial sobre o Meio Ambiente, desenvolvimento sustentável é aquele que responde às necessidades do presente sem comprometer as gerações futuras (CMIMAD, 1991). Conforme Tashizawa (2002, p. 28), “[...] a gestão ambiental envolve a passagem do pensamento mecanicista para o sistêmico, no qual um aspecto essencial dessa mudança é que a percepção do mundo como máquina cede lugar à percepção

REAd | Porto Alegre - Edição 86 - No 2 - Maio / Agosto 2017 - p. 31 - 57 
como sistema vivo". Ou seja, a incorporação dos atributos da GSI traz, à rotina executiva, um novo estilo de gestão, por demandar uma ética preocupada com as gerações futuras, inclusive da própria sobrevivência das organizações. Assim, temas relacionados à proteção da vida e às melhorias do meio ambiente e da qualidade de vida são assuntos relevantes para o desenvolvimento sustentável.

Alcançar o desenvolvimento sustentável requer uma aproximação integral aos processos econômicos, sociais e ambientais. Costa, Cohen e Schaeffer (2007), entretanto, sustentam que os discursos sobre o desenvolvimento sustentável têm sido historicamente enfocados nas dimensões ambiental e econômica, deixando de lado as questões política e social, e que estas dimensões são intrinsecamente dependentes. Para esses autores, apesar do bom senso, o conceito de desenvolvimento sustentável é vago, por não indicar os caminhos a seguir para atingi-lo. Por isso, setores diferentes da sociedade tendem a interpretá-lo de acordo com seus próprios interesses, percepções e necessidades.

Alves (2002) esclarece ser inegável a contribuição das empresas na criação da riqueza humana, bem como a sua importância ao longo da vida das pessoas. Elas são verdadeiras fontes de progresso econômico e de bem-estar social. Contudo, acrescenta o autor, de sua atuação também surgem consequências indesejáveis, como poluição ambiental, prejuízos às saúdes humana e animal, desvios na ordem da conduta moral, abusos de poder econômico e, por fim, distorções perversas no funcionamento da economia.

Esses aspectos negativos representam um custo social que se paga para obter as vantagens decorrentes da existência das empresas. O que se advoga não é apenas a adoção de um posicionamento preservacionista, mas sim o desenvolvimento de uma perspectiva socioambiental, que objetiva utilizar recursos eficientemente, conciliando crescimento econômico, avanços tecnológicos e limitações ecológicas (JABBOUR; SANTOS, 2006). Para Nascimento (2005), a gestão socioambiental precisa trazer resultados no presente e contribuir para o futuro da empresa.

A crise ambiental veio questionar os fundamentos ideológicos e teóricos que impulsionaram e legitimaram o crescimento econômico, negando a natureza e a cultura, deslocando a relação entre o real e o simbólico. A sustentabilidade ecológica aparece, assim, como um critério normativo para a reconstrução da ordem econômica, como condição para a sobrevivência humana e para um desenvolvimento durável (LEFF, 2006).

O desenvolvimento sustentável, assim como a construção de um negócio bem sucedido, requer uma visão de longo prazo e também “[...] considerações sociais, ambientais e 
econômicas que sejam integradas entre si, possibilitando julgamentos equilibrados sobre diversas questões que permeiam essa visão de longo prazo" (HOLME; WATTS, 2000, p.3).

Por isso, “[...] as organizações que tomarem decisões estratégicas integradas à questão ambiental e ecológica conseguirão significativas vantagens competitivas, quando não, redução de custos e incremento nos lucros a médio e longo prazos" (TASHIZAWA, 2002, p.24). Não por acaso, o conceito de sustentabilidade empresarial desenvolvido pelo Instituto Ethos de Responsabilidade Social ${ }^{\mathrm{v}}$ é o de assegurar o sucesso do negócio no longo prazo e, ao mesmo tempo, contribuir para o desenvolvimento econômico e social da comunidade, constituindo um meio ambiente saudável e uma sociedade estável (GONÇALVES, 2006).

As ações e pressões para que as empresas minimizem os seus riscos ambientais, por parte dos órgãos reguladores, dos investidores, das instituições financeiras, dos acionistas, dos consumidores e das entidades de diversas naturezas, as têm levado a desenvolverem produtos e serviços que causem menores impactos ambientais, e a buscarem novas formas de relacionamento com o meio na qual estão inseridas.

Visando a colaborar nesse aspecto, em 2006 o British Standards Institute(BSI) ${ }^{\mathrm{vi}}$ lançou a norma BS 8900:2006 intitulada Diretrizes para a Gestão do Desenvolvimento Sustentável.

Esse regulamento indica como as melhorias para o desenvolvimento sustentável podem ser conseguidas por meio do fortalecimento das relações, do aumento da coesão interna, da construção da confiança, do estímulo ao aprendizado, e do gerenciamento dos riscos e das oportunidades dentro da organização. Além disso,orienta quanto à gestão da sustentabilidade, por meio do balanceamento entre os aspectos econômico, ambiental e social do negócio, tendo em vista a melhoria contínua do desempenho e a responsabilidade das organizações. Assim, ela ajuda as empresas a fazer a conexão entre as normas existentes relacionadas com o tema, a exemplo da série ISO 14000 e das diretrizes Global ReportingInitiative $(\mathrm{GRI})^{\mathrm{vii}}$.

O crescimento, a rentabilidade e a geração de resultados econômicos da empresa devem ser concomitantes com o desenvolvimento da sociedade e com a preservação do meio ambiente. Trata-se da essência do TrippleBottomLine(TBL) ${ }^{\text {viii }}$ cuja mensagem é que as “[...] empresas precisam considerar na sua gestão a complexidade inerente ao ato de fazer negócios na sociedade contemporânea, para isso, devem considerar seus resultados nas dimensões ambiental, social e econômica" (GONÇALVES, 2006, p.23).

Assim, são muitas as dificuldades para pensar em sustentabilidade: distribuição de renda desigual, a pobreza, a falta de educação, desequilíbrio espacial, entre outros. Buarque 
(2004) resume que não poderemos assumir compromissos com o futuro desconsiderando o presente.

A ação dos gestores e o comportamento organizacional na esfera ambiental vêm sendo tratados como uma resposta racional imposta pelos desafios que, a partir das três últimas décadas, a questão ambiental vem originandoaos empreendimentos (GOBBI, 2005). Benefícios tangíveis, típicos dos conquistados na implantação de um Sistema de Gestão Ambiental, como redução de custos, melhoria de produtividade, crescimento de receitas, acesso a mercados, e melhoria na relação com os colaboradores, foram alcançados por empresas que optaram pelo caminho da sustentabilidade.

No entanto, ganhos intangíveis também devem ser contabilizados, como valorização da imagem institucional, maior lealdade do consumidor, maior capacidade de atrair e de manter talentos, capacidade de adaptação, longevidade e diminuição de conflitos (YOUNG, 2005).

As características que sempre definiram uma marca - como os benefícios intrínsecos, o preço, a distribuição e a individualidade - agora devem agregar outros fatores, entre esses a origem da matéria-prima, as condições de produção e os impactos socioambientais. A construção de uma empresa sustentável, em resposta a muitas organizações 'tradicionais' que enfocam apenas o crescimento econômico, deve desenvolver-se com base no equilíbrio entre as dimensões social, ambiental e econômica.

No presente estudo, foi elaborado esquema conceitual da GSI, que tem, por princípio, que as dimensões social, ambiental e econômica devem ser entendidas como o resultado da integração de políticas e de atividades que busquem estar de acordo com a RSC, com a gestão ambiental corporativa e com o Marketing ambiental.

Ressalta-se que a gestão organizacional, com base na GSI, tem, como prerrogativa básica, a relação ética e transparente da organização com todas as partes interessadas em suas atividades. Por isso, ela busca planejar, dirigir, controlar e alocar recursos, com o objetivo de promover o desenvolvimento da sociedade, preservando os recursos naturais e culturais por meio de um gerenciamento responsável que respeita a diversidade e que reduz desigualdades, com a concomitante tarefa de satisfazer as necessidades de seus clientes de modo sustentável e lucrativo para as organizações.

\section{A FACE DO MARKETING AMBIENTAL}

Consumo sustentável foi definido pelo Relatório Brundtland ${ }^{\text {ix }}$ como a ação que atende às necessidades atuais sem comprometer a capacidade das futuras gerações em satisfazer suas

REAd | Porto Alegre - Edição 86 - No 2 - Maio / Agosto 2017 - p. 31 - 57 
próprias necessidades (WCED, 1987). Na esteira desse significado, o Plano de Ação denominado Rio+10, que surgiu da Cúpula Mundial sobre Desenvolvimento Sustentável ${ }^{\mathrm{X}}$, declara que "[...] mudanças fundamentais na forma das sociedades produzirem e consumirem são indispensáveis para a conquista de um desenvolvimento sustentável global" (BRENDE, 2004, p.29).

A busca desenfreada do consumo impôs um alto custo, que cresce pelo menos tão rápido quanto o próprio consumo, que hoje absorve grandes quantidades de recursos, muitos dos quais estão sendo consumidos além dos níveis de sustentabilidade (FLAVIN, 2004). O consumo é essencial para o bem-estar da humanidade, no entanto o consumo exagerado ou errado prejudica tanto a nossa saúde pessoal quanto a saúde do meio ambiente natural de que dependemos. Novos padrões de consumo serão necessários para retirar bilhões de pessoas da pobreza de uma forma consistente com a sustentabilidade global (BRENDE, 2004).

Jackson e Michaelis (2003) enumeraram cinco estratégias essenciais para que seja possível atingir o consumo sustentável: (1) alinhar as visões estratégica, retórica e prática; (2) formatar o contexto cultural do consumo; (3) financiar iniciativas nãogovernamentais e inovação; (4) estabelecer programas e redes a fim de identificar as iniciativas bem sucedidas e encorajar as suas replicações e; (5) monitorar e aprender com os resultados.

Se, para o indivíduo enquanto cidadão ou consumidor, interessam bons produtos, taxa aceitável de desemprego e preservação ambiental, não se pode dizer que esses interesses não são conciliáveis com os interesses empresariais que gravitam na obtenção do lucro das suas atividades - e que, para obtê-los, carece de atender às necessidades de seus clientes (PINHEIRO et al., 2006).

Os consumidores começaram a exigir comportamento ético por parte das empresas, voltado a valores humanistas e ligado à sustentabilidade e à qualidade de vida da sociedade e do planeta: "O consumidor mudou seu comportamento de compra, punindo empresas que descuidam do meio ambiente e, inversamente, valorizando as que têm uma atitude responsável" (MATAR, 2002, p.4).

Assim, avisão sobre o papel das corporações brasileiras tem apresentado sinais de mudança, conforme as grandes empresas verificam que as ações de responsabilidades social e ambiental, com transparência e credibilidade, aumentam o valor da marca (RIBAS; SMITH, 2006).Entretanto, acrescentam os autores, ações sociais não se sustentam se não estiverem calcadas em uma filosofia de gestão. Ou seja, a responsabilidade social só é reconhecida quando se caracteriza como uma diretriz da empresa, que permeia todas as ações organizacionais.

REAd | Porto Alegre - Edição 86 - No 2 - Maio / Agosto 2017 - p. 31 - 57 
Com a expansão da responsabilidade social e o crescente interesse dos clientes e da sociedade no tema, comunicar, para diferentes partes interessadas, aquilo em que as empresas acreditam, no que pensam e como agem, passou a ser uma estratégia de afirmação de princípios (GUERREIRO, 2007).

A face do Marketing ambiental da GSI deve ser construída com base nesses pressupostos, considerando que é representada pelos esforços das organizações em satisfazer as expectativas dos consumidores por produtos que determinem menores impactos ambientais ao longo do seu ciclo de vida (OTTMAN, 1993). Isso porque o Marketing ambiental incorpora um amplo leque de atividades, incluindo a modificação de produtos, mudanças no processo de produção, e alteração das atividades de embalagens, assim como modificações nos anúncios e nas propagandas (POLONSKY, 2001).

Com isso, oMarketing ambiental está evoluindo para um processo holístico de gerenciamento, responsável por identificar, antecipar e satisfazer as necessidades dos clientes e da sociedade de um modo lucrativo e sustentável(PEATTIE; CHARTER, 2005), não devendo limitar-se ao desenvolvimento de produtos que tenham alguns atributos verdes (OTTMAN, 1993). Ou seja, as empresas começaram a reconhecer que a resposta às questões ambientais é algo pelo qual se interessam clientes, investidores e outros, e que pode proporcionar oportunidades para inovações e para ampliações de vantagens competitivas (PEATTIE; CHARTER, 2005).

Para Ottman (1993), o Marketing ambiental é complexo e requer novas estratégias que, efetivamente, abordem desafios-chave relacionados com a maneira como são definidos os produtos verdes que os consumidores realmente apreciarão, e como comunicar esses atributos. Assim, há cinco possíveis razões que têm levado as organizações a adotar o Marketing ambiental (POLONSKY, 2001): (1) identificação de oportunidades que podem ajudá-las a alcançar seus objetivos; (2) crença de que têm uma obrigação moral de serem mais responsáveis socialmente; (3) constatação de que as atividades dos órgãos governamentais estão pressionando as empresas a tornarem-se mais responsáveis; (4) observação de que as atividades ambientais dos concorrentes pressionam as organizações a alterarem as suas atividades e; (5) consideração de fatores relacionados a custos associados à eliminação de desperdícios ou a reduções de utilização de matéria-prima.

Isso não implica dizer que todas as empresas que adotam o Marketing ambiental realmente aperfeiçoaram o seu comportamento. Muitos custos ambientais da produção e do consumo não estão sendo refletidos totalmente - quer diretamente, quer indiretamente via tributação - nas estruturas de custo de empresas e nos preços pagos por seus clientes. Isso

REAd | Porto Alegre - Edição 86 - No 2 - Maio / Agosto 2017 - p. 31 - 57 
significa que "[...] a sociedade e o ambiente estão correntemente subsidiando nosso consumo e nossa produção.”. (PEATTIE; CHARTER, 2005, p.536).

\section{A FACE DA RESPONSABILIDADE SOCIAL CORPORATIVA (RSC)}

A RSC pode ser entendida como uma forma de "[...] gestão que se define pela relação ética e transparente da empresa com todos os públicos com os quais ela se relaciona e pelo estabelecimento de metas empresariais compatíveis com o desenvolvimento sustentável da sociedade" (ETHOS, 2007, p.1).

Trata-se de conceito que envolve a ação e a participação dos stakeholderspara a definição de políticas, de diretrizes, de atividades e de ações que serão adotadas pela organização. Porém, cabe ressaltar que existe um conjunto de valores que devem ser considerados preliminarmente, sendo eles o respeito aos direitos humanos e aos direitos trabalhistas, a proteção e a conservação ambientais, e a valorização das comunidades e do desenvolvimento social.

Responsabilidades éticas correspondem a atividades, práticas, políticas e comportamentos esperados (no sentido positivo) ou proibidos (no sentido negativo) por membros da sociedade, apesar de não codificados em lei. Elas envolvem uma série de normas, de padrões ou de expectativas de comportamento para atender o que os diversos públicos com os quais a empresa se relaciona - os stakeholders - consideram legítimo, correto, justo ou de acordo com seus direitos morais ou expectativas (BORINELLI; VENTURA, 2004).

A “[...] empresa que quer ser sustentável inclui entre seus objetivos o cuidado com o meio ambiente, o bem-estar dos seus stakeholderse a constante melhoria da sua própria reputação" (ALMEIDA, 2002, p.81). Ou seja, aRSC representa uma transformação na concepção da empresa e de seu papel na sociedade, uma vez que se funda numa nova visão da realidade econômica. Elapropõe um novo modo de conceber as relações entre os fatores de produção, em particular entre o capital e o trabalho, donde decorre uma nova concepção da empresa e de seu papel na sociedade, assim como o reconhecimento de que as decisões dos resultados das atividades das corporações alcançam um universo de agentes sociais bem mais amplo do que o composto por seus sócios e acionistas (BORGER, 2001).

As maiores apreensões sociais em relação ao aumento da degradação ambiental e da desigualdade social, à diminuição do poder e do escopo dos governos, à globalização, ao maior alcance da mídia, a avanços na tecnologia da informação, entre outros fatores, formam 
um arranjo de forças externas que contribuem para o crescimento da implantação, do desenvolvimento e da importância da RSC.

Outro fator determinante que leva as organizações a refletirem sobre a implantação da RSC refere-se à necessidade de resguardar a reputação da empresa e a imagem de suas marcas dentro de um mercado cada vez mais competitivo. As empresas serão penalizadas pelos consumidores por ações que não sejam consideradas responsáveis socialmente. "Ser socialmente responsável não é apenas a melhor coisa a ser feita, a implantação da RSC pode distinguir uma companhia das suas concorrentes" (SMITH, 2003, p.62).

As políticas socialmente responsáveis e o respeito por valores morais e sociais constituem os indicadores teóricos do desempenho social da empresa(DSE), indicador que compreende três componentes: o nível de responsabilidade social, o comprometimento com causas sociais, e a filosofia subjacente à resposta das empresas perante problemas ou desafios de natureza social (CARROLL, 1979).

Wartick e Cochran (1985) concretizam a definição de DSE na observação de três dimensões da atividade empresarial: os princípios(valores que orientam as políticas de RSC), os processos(mecanismos utilizados para atuar socialmente) e as políticas sociais. Atualmente, preço e qualidade são condições que já se tornaram obrigatórias para o desempenho de qualquer produto ou serviço: “As empresas que desejam diferenciar-se no mercado global devem adicionar à sua gestão aspectos que estiveram muito distantes ao longo da história do capitalismo, isto é, a união entre o fator econômico e o fator social" (URSINI; BRUNO, 2005, p.3).

\section{A FACE DA GESTÃO AMBIENTAL CORPORATIVA}

A consciência ambiental está ganhando dimensão e situando o meio ambiente como um dos princípios fundamentais do ser humano. Os gastos com proteção ambiental começam a ser vistos não apenas como custos, mas sim como investimentos. A gestão ambiental significa mais do que apenas o gerenciamento de riscos e de perigos potenciais e não apresenta restrições, podendo ser aplicada em qualquer empresa ou indústria, independente do porte e do ramo de atuação.

A preocupação permanente com a mitigação deste impacto é essência da ecoeficiência, definida pelo The World Business Council for SustainableDevelopment ${ }^{\mathrm{xi}}$ (WBCSD, 2000) como a entrega de bens e de serviços a preços competitivos, que satisfazem as necessidades humanas e que trazem qualidade de vida a reduzido custo ecológico e a baixa intensidade do uso dos recursos naturais, alinhados com a capacidade de assimilação do planeta.

Partindo deste enfoque, a introdução do conceito de prevenção é fundamental, pois REAd | Porto Alegre - Edição 86 - No 2 - Maio / Agosto 2017 - p. 31 - 57 
reduz cada vez mais a geração de resíduos na origem, ao contrário do que acontece no caso de uma postura reativa (BARBIERI, 2004). Ademais, os esforços pela melhoria ambiental tradicionalmente negligenciam os custos de processo: “Companhias e órgãos reguladores mais avançados adotaram o conceito da prevenção da poluição, que utiliza métodos de substituição de materiais e processos para eliminar ou limitar a poluição antes que ela ocorra" (PORTER; LINDE, 1995, p.10).

Muitas organizações adotaram práticas de tratamento e de controle da poluição, conhecidas como tecnologia de controle de final do processo (em inglês, end-of-pipecontrol). Contudo, essas práticas não evitam a emissão de poluentes, são caras e não melhoram a produtividade dos processos, além de não agregarem valores às organizações (DIAZ; PIRES, 2005).

Conforme estabelece a NBR-14000 - versão brasileira do conjunto de normas da ISO $14000^{\mathrm{xii}}$ - o setor industrial, um dos principais responsáveis pela grave situação ambiental com relação aos seus resíduos, vem tomando medidas proativas, tais como produção mais limpa, certificação ambiental, redução de resíduos tóxicos, reciclagem e reuso, e avaliação do ciclo de vida do produto.

A família de normas ISO14000 se constitui em uma ferramenta criada para auxiliar as empresas a identificar, a priorizar e a gerenciar seus riscos ambientais, fazendo com que atentem às questões relacionadas com o meio ambiente, e exigindo o comprometimento com a prevenção da poluição e com o programa de melhorias contínuas.

Essas normas têm caráter voluntário, que aborda a gestão ambiental por meio de uma sequência de procedimentos relacionados a sistemas de gestão, de auditoria, de avaliações do desempenho e do ciclo de vida do produto, de rotulagem e de aspectos ambientais em normas de produtos. Seu foco é na ação e no pensamento proativo e não em reação a comandos e em políticas de controle (MARSHALL JR, 2003).

Essa tendência estrutura os sistemas integrados de gestão, que geralmente se consolidam com base na família de normas ISO 9000 (gestão da qualidade), ISO 14000 (gestão ambiental), SA 8000 (responsabilidade social), BS 8800 E OHSAS 18001 (gestão de saúde e segurança ocupacional). Com essas certificações, a empresa demonstra, aos seus clientes e à sociedade, sua responsabilidade para com o meio ambiente, além de estar em conformidade com as exigências da norma.

Nesse contexto, a gestão ambiental passou a ter importante papel para conciliar a ampliação dos ganhos econômicos com a conservação do meio ambiente. Nota-se, também, que diversas empresas estão buscando estas certificações, preocupando-se com os resíduos REAd | Porto Alegre - Edição 86 - No 2 - Maio / Agosto 2017 - p. 31 - 57 
gerados não só na questão quantitativa, mas também qualitativa. Também buscam repensar o desenvolvimento de novos produtos, considerando a reutilização e o aproveitamento dos próprios resíduos, e promovendo a redução dos passivos ambientais.

A face da gestão ambiental da GSI deve ser construída considerando um conjunto de atividades, tais como planejamento, direção, controle, alocação de recursos e outras. Essas atividades devem objetivar a obtenção de efeitos positivos sobre o meio ambiente, quer reduzindo ou eliminando os danos ou problemas causados pelas ações humanas, quer evitando que eles surjam (BARBIERI, 2004).

\section{MÉTODO}

A escolha do método se pautou por sua capacidade de permitir a validação do esquema conceitual Pirâmide da Sustentabilidade Empresarial. Assim, tratou-se de pesquisa de abordagem quantitativa, com finalidade exploratória - vez que existiam poucos conhecimentos acumulados em relação à situação específica de implantação de mecanismos de sustentabilidade empresarial nas organizações estudadas.

Quanto aos meios, foi elaborado estudo comparativo entre três unidades de análise, respectivamente pertencentes a setores da economia relacionados ao fornecimento de energia elétrica, saneamento ambiental e transporte rodoviário urbano de passageiros, prestadores desses serviços à população do município de Cabo Frio, localizado na Região dos Lagos do estado do Rio de Janeiro. A escolha por um estudo comparativo remete a ele poder basear-se em semelhanças ou diferenças (ROESH, 1999). No caso, baseou-se nas semelhanças existentes entre as organizações envolvidas: todas são privadas, prestam serviços à população de um mesmo município e operam basicamente sem concorrência, mediante concessões provenientes de órgãos públicos.

A pesquisa foi desenvolvida em duas etapas distintas:

1)Investigação bibliográfica: foi construído referencial teórico para a sustentação do esquema conceitual Pirâmide da Sustentabilidade Empresarial. No caso, foram identificados e analisados os conceitos relacionados aos conceitos de responsabilidade social empresarial, de gestão ambiental e de Marketing ambiental, que são as faces da Pirâmide da Sustentabilidade Empresarial representativas das dimensões social, ambiental e econômica das relações organizacionais. Em paralelo, foi desenvolvida pesquisa relacionada à educação socioambiental, base de sustentação da Pirâmide da Sustentabilidade Empresarial.

2) Identificação, classificação e seleção dos atributos críticos da Pirâmide da Sustentabilidade Empresarial, etapa dividida em três fases: 
2.1) Identificação dos atributos críticos: foram buscados elementos para a construção dos atributos críticos da Pirâmide da Sustentabilidade Empresarial com base em indicadores que pudessem ajudar no conhecimento da realidade estudada (BESSERMAN, 2005). Para tanto, foram utilizados dados secundários, com base em diversas origens (ETHOS, 2006; NBR ISO 14001, 1996; NBR ISO 14004, 1996; POLONSKY, 2001; PEATTIE; CHARTER, 2005).

2.2) Classificação dos atributos críticos: primeiramente foi efetivada pesquisa de campo, com aplicação de um questionário submetido a especialistas, para posterior utilização do método Delphi, o qual busca fazer emergir consenso entre especialistas, cujas opiniões sobre o assunto em pauta "são obtidas e refinadas num processo de interação em que o número de consultas é repetido algumas vezes" (RIBAS, 1995, p.60). Por seu turno, esses especialistas foram selecionados de forma não probabilística por julgamento do autor da pesquisa, tendo compreendido 15 profissionais com notório saber e participação relevante na área objeto da pesquisa.

2.3) Seleção dos atributos críticos: foi definido corte na sua classificação, utilizando a distribuição normal $\mathrm{t}$ de Student como parâmetro estatístico de definição dos atributos.

Os atributos pertencentes às três faces foram mensurados por meio de uma escala de diferencial semântico com sete pontos. Em seguida foi efetuado um pré-teste envolvendo amostra com 57 usuários, obtida por procedimento aleatório e sistemático. A análise prévia dos dados permitiu verificar: (a) como os usuários percebem as organizações pesquisadas em relação às suas ações nas dimensões social e ambiental; (b) as principais diferenças de percepção entre as organizações; e (c) quais ações deveriam ser empreendidas para melhorar o posicionamento destas organizações com relação aos requisitos identificados na GSI.

\section{RESULTADOS}

As referências bibliográficas serviram de base para a elaboração de uma lista de indicadores que caracterizam a RSC (ver Quadro 1), assim como possibilitaram elaborar as listas de indicadores que caracterizam a gestão ambiental corporativa (ver Quadro 2) e das ações de Marketing ambiental (ver Quadro 3). 


\begin{tabular}{|c|c|}
\hline Indicador & Descrição \\
\hline Adota compromissos éticos abrangentes & A ações empresariais são coerentes e éticas em todos os aspectos \\
\hline Pratica a governança corporativa & Adoção e divulgação rotineira de critérios socioambientais \\
\hline Envolve os empregados na gestão & Representante dos empregados no Conselho de Administração \\
\hline Cultura organizacional com valores éticos & Eficiência na disseminação dos valores e princípios éticos \\
\hline Diálogo transparente comstakeholders & Participação destes nas decisões e atividades da organização \\
\hline Política de remuneração e de benefícios & Plano de carreira, benefícios e aposentadoria, salário variável \\
\hline Cuida a saúde e segurança no trabalho & Ações e processos que asseguram condições ideais de trabalho \\
\hline Compromete-se com futuro das crianças & Adota ações previstas no Estatuto da Criança e do Adolescente \\
\hline Divulga o Balanço Social & Dissemina de modo amplo e periódico as ações socioambientais \\
\hline Envolve-se em ações sociais & Compartilha as competências técnica e gerencial com a sociedade \\
\hline Relaciona-se com organizações locais & Atua em parceria com ONGs e instituições comunitárias \\
\hline Financia ações sociais estruturadas & Participa de ações sociais com resultados visíveis e coerentes \\
\hline Exerce influência social em fóruns & Ativa e formadora de opinião em comitês e eventos comunitários \\
\hline Busca formar cidadãos com educação & Investe em programas de formação profissional na comunidade \\
\hline Prática de anticorrupção e de propinas & Possui práticas punitivas que coíbem a corrupção de agentes \\
\hline Participa em projetos sociais públicos & Faz parte de projetos público-privados sem fins lucrativos \\
\hline Promove a não discriminação racial & Estimula a diversidade racial na contratação e na capacitação \\
\hline Busca do desenvolvimento profissional & Promove a capacitação e o desenvolvimento continuado \\
\hline Fortalece relações com Sindicatos & Respeita os acordos sindicais e a participação dos empregados \\
\hline Valoriza a diversidade na sociedade & Combate a discriminação social em todas as suas formas \\
\hline Compromisso com a equidade de gênero & Possui participação feminina importante nos cargos gerenciais \\
\hline Beneficia trabalhadores terceirizados & Os terceirizados têm benefícios semelhantes aos dos empregados \\
\hline Busca erradicar o trabalho infantil & Não possui fornecedores que utilizam o trabalho infantil \\
\hline Compromisso desenvolvimento infantil & Investe em programas educacionais e recreativos para crianças \\
\hline Busca erradicar o trabalho escravo & Não possui fornecedores que utilizam o trabalho forçado \\
\hline Prepara para a aposentadoria & Possui plano de aposentadoria e associação de aposentados \\
\hline Apoia empregado após sua demissão & Apoia na recolocação e tem benefícios por tempo determinado \\
\hline Transparente com campanhas políticas & Financia campanhas de forma objetiva, justa e transparente \\
\hline
\end{tabular}

Quadro 2 - Ações de Gestão Ambiental Corporativa: Indicadores e Respectivas Descrições

\begin{tabular}{|l|l|}
\hline \multicolumn{1}{|c|}{ Indicador } & \multicolumn{1}{c|}{ Descrição } \\
\hline Cumprimento da legislação ambiental & Obedecea legislação ambiental (Conama, Código Florestal) \\
\hline Gestão do ciclo de vida dos produtos & Trabalha com engenharia reversa \\
\hline Melhoria ambiental em processos & Baixa emissão de poluentes e resíduos caracteriza seus processos \\
\hline Seriedade com impactos ambientais & Possui estudos de impactos ambientais e age de modo proativo \\
\hline Conscientização ambiental à comunidade & Fornece cartilhas educacionais e palestras ambientais \\
\hline Controla o risco de acidentes ambientais & Possui planos de mitigação e de ação em caso de catástrofes \\
\hline Busca reduzir o consumo de água & Utiliza procedimentos de reciclagem e ciclo fechado de água \\
\hline Conscientização ambiental empregados & Proporciona cursos de educação ambiental aos empregados \\
\hline Ciência dos danos potenciais de produtos & Elaborou um estudo das consequências do descarte ou vazamento \\
\hline Busca reduzir o consumo de energia & Utiliza,sempre que possível, fontes renováveis de energia \\
\hline Investe e busca reduzir poluentes & Possui sistemas de controle e filtragem de gases e efluentes \\
\hline Investe e promove redução de resíduos & Participa de programas que orientam a reduzir o descarte \\
\hline Reduz o consumo de matéria-prima & Trabalha com análise de valor visando a redução de materiais \\
\hline Investe promove reutilização de resíduos & Utilização de embalagens refil e a cogeração de energia \\
\hline Investe e promove reciclagem de resíduos & Promove e estimula a reciclagem de embalagens e descarte \\
\hline
\end{tabular}

Fonte: Elaboração própria

\section{Quadro3 - Ações de Marketing Ambiental: Indicadores e Respectivas Descrições}

\begin{tabular}{|l|l|}
\hline \multicolumn{1}{|c|}{ Indicador } & \multicolumn{1}{c|}{ Descrição } \\
\hline Fornecedores possuem respeito ambiental & Possui apenas fornecedores que obedecem a legislação ambiental \\
\hline Investe em projetos c/ proteção ambiental & O respeito ao meio ambiente é um critério de seleção de projetos \\
\hline Combate práticas desleais concorrência & Não aceita reduzir o custo se vier a prejudicar o meio ambiente \\
\hline
\end{tabular}

REAd | Porto Alegre - Edição 86 - No 2 - Maio / Agosto 2017 - p. 31 - 57 


\begin{tabular}{|l|l|}
\hline Atendimento com diálogo e engajamento & Promove parcerias com organizações ligadas ao meio ambiente \\
\hline Inovações p/ reduzir impactos ambientais & Possui investimentos em P\&D com ênfase ambiental \\
\hline Consciência sobre formação de valores & Divulga a proteção ao ambiente nos meios de comunicação \\
\hline Possui produtos seguros para o ambiente & Os produtos possuem certificação ambiental (ex: ISO 14000) \\
\hline Visão ambiental da cadeia suprimentos & Observa o impacto ambiental desde a fase extrativa \\
\hline Educa consumidor para causa ambiental & Passa o respeito ao ambiente na propaganda e nas embalagens \\
\hline Oferece produtos com maior durabilidade & Desestimula mudanças de versão e incrementalismo excessivo \\
\hline Apoia a educação dos fornecedores & Busca adequar os fornecedores aos requisitos ambientais \\
\hline Indicam aspectos ambientais nos rótulos & Esclarece o consumidor sobre como descartar a embalagem \\
\hline Produtos com facilidade de reciclagem & Utiliza embalagens que sejam recicláveis ou perecíveis \\
\hline Destinação final adequada aos resíduos & Prepara locais para o armazenamento ou eliminação dos resíduos \\
\hline Evita criar passivos ambientais & Busca mitigar os impactos no mesmo local onde estes ocorrem \\
\hline
\end{tabular}

Fonte: Elaboração própria

Conforme a metodologia proposta, os indicadores foram apresentados a um grupo de especialistas composto por 15 sujeitos, todos com formação de nível superior e com especialização nas suas áreas de atuação. As graduações dos especialistas ocorreram nas áreas das ciências sociais, humanas e exatas, representadas por formações em Administração, Arquitetura, Biologia, Ciências Contábeis, Economia, Engenharia, Direito, Psicologia e Serviço Social. As pós-graduações se subdividiram em cinco lato sensu e 10stricto sensu, sendo nove em nível de mestrado e uma em nível de doutorado.

A Tabela 1 contém os escores subjetivos para as ações de RSC, sendo atribuídos os valores iguais a 3 para um fator crítico de sucesso, 2 para um fator relevante e 1 para um fator complementar, sendo os fatores críticos limitados a um máximo de três.

Tabela1 - Escores Subjetivos para as Ações de Responsabilidade Social Corporativa (RSC)

\begin{tabular}{|c|c|c|c|c|c|c|c|c|c|c|c|c|c|c|c|}
\hline Indicador & $\mathbf{A}$ & $\mathbf{B}$ & $\mathbf{C}$ & D & $\mathbf{E}$ & $\mathbf{F}$ & $\mathbf{G}$ & $\mathbf{H}$ & I & $\mathbf{J}$ & $\mathbf{K}$ & $\mathbf{L}$ & $\mathbf{M}$ & $\mathbf{N}$ & $\mathbf{O}$ \\
\hline Adota compromissos éticos abrangentes & 3 & 3 & 3 & 3 & 3 & 2 & 3 & 2 & 3 & & 3 & 3 & 3 & 3 & 3 \\
\hline Pratica a governança corporativa & & 2 & 2 & 3 & & 3 & 2 & 3 & 3 & 2 & 2 & 3 & 3 & & 2 \\
\hline Envolve os empregados na gestão & 3 & & 2 & 3 & & 3 & 3 & 1 & & 1 & 2 & 3 & 1 & 1 & 2 \\
\hline Cultura organizacional com valores éticos & & 2 & & & & & 3 & 2 & 2 & & 1 & 2 & 2 & 3 & 3 \\
\hline Diálogo transparente comstakeholders & 1 & 3 & 2 & & 2 & 2 & 2 & & 2 & & 1 & 1 & & & 3 \\
\hline Política de remuneração e de benefícios & 2 & & & 2 & 2 & 3 & 2 & 2 & 1 & 2 & 2 & 2 & & & \\
\hline Cuida a saúde e segurança no trabalho & 2 & 2 & & 1 & 2 & 2 & 2 & & 3 & & 1 & 1 & 2 & 1 & 1 \\
\hline Compromete-se com futuro das crianças & 1 & & 3 & 2 & 2 & & 1 & 1 & & 1 & 2 & 2 & 2 & 2 & \\
\hline Divulga o Balanço Social & & 3 & 2 & 2 & & 2 & 2 & & 1 & & 3 & & & & 2 \\
\hline Envolve-se em ações sociais & & 2 & 2 & & 1 & & & 1 & 2 & 2 & 2 & & 3 & & 2 \\
\hline Relaciona-se com organizações locais & 2 & 2 & 1 & & 1 & 2 & & 2 & & 1 & & 2 & 2 & & 2 \\
\hline Financia ações sociais estruturadas & 3 & 2 & & 2 & & & & & 1 & 2 & & & 1 & 3 & 1 \\
\hline Exerce influência social em fóruns & & & 1 & & & 1 & & 3 & 2 & 3 & 1 & & & & 2 \\
\hline Busca formar cidadãos com educação & 1 & 1 & & 1 & 1 & 1 & 1 & & 1 & 3 & 3 & 2 & & & 2 \\
\hline Prática de anticorrupção e de propinas & & 1 & & 2 & 2 & & & & 2 & 2 & & 2 & 1 & 1 & \\
\hline Participa em projetos sociais públicos & 1 & & 2 & 1 & & 1 & 1 & 2 & & 3 & & & & & 1 \\
\hline Promove a não discriminação racial & & & & 2 & 3 & & & 1 & & & & 1 & 2 & 2 & \\
\hline Busca do desenvolvimento profissional & 2 & & & & 1 & 2 & & & 2 & 2 & & 1 & 1 & & 1 \\
\hline Fortalece relações com Sindicatos & & & 1 & 1 & 1 & 1 & 1 & 3 & & & 1 & & & & \\
\hline Valoriza a diversidade na sociedade & 2 & 1 & & & & & & 1 & 1 & & & 2 & & 1 & 1 \\
\hline Compromisso com a equidade de gênero & 1 & & & & 3 & & & & 1 & & & & 1 & 2 & \\
\hline Beneficia trabalhadores terceirizados & & 1 & 1 & & & & 2 & 2 & & 1 & 1 & & & & \\
\hline
\end{tabular}




\begin{tabular}{|c|c|c|c|c|c|c|c|c|c|c|}
\hline Busca erradicar o trabalho infantil & & & & 2 & 1 & & 1 & & 1 & 2 \\
\hline Compromisso desenvolvimento infantil & & & & & & 1 & 1 & 2 & 1 & 2 \\
\hline Busca erradicar o trabalho escravo & & & & 1 & & & & & 2 & 2 \\
\hline Prepara para a aposentadoria & 2 & 1 & 1 & & & & & & 1 & 1 \\
\hline Apóia empregado após sua demissão & 1 & 1 & 1 & & & & & & & \\
\hline Transparente com campanhas políticas & & 1 & & & & & & & & \\
\hline
\end{tabular}

Observando a ordem de prioridade na ordenação dos itens, constata-se que os cinco atributos considerados como possuidores de maior relevância estão vinculados à transparência na gestão e ao envolvimento dos stakeholders.

Nessa ótica, espera-se que a empresa adote valores e princípios éticos de modo contínuo e abrangente. Tais princípios devem ser disseminados para dentro, envolvendo os empregados nas decisões estratégicas, tornando o processo participativo inerente à identidade empresarial. A empresa deve comprometer-se e incorporar critérios de ordem socioambiental na gestão.

Os compromissos éticos das organizações devem ser concretizados por meio de ações efetivadas através de um modelo de governança corporativa que assuma e incorpore critérios de ordem socioambiental na gestão dos negócios organizacionais. Esse modelo deve vir acompanhado de uma gestão participativa, do enraizamento de valores e éticos na cultura organizacional, do combate à corrupção e com a necessária informação à comunidade de interesse nas atividades desenvolvidas pela organização através da divulgação dos balanços socioambientais.

A importância do diálogo com as partes interessadas é ratificada por meio da seleção de outros atributos relacionados com os empregados (política de remuneração, benefícios e condições de trabalho; cuidados com a saúde, segurança e condições de trabalho), com a comunidade (relações com organizações locais; compromisso com o futuro das crianças; financiamento da ação social, envolvimento da empresa com a ação social e construção da cidadania pelas empresas), com os parceiros organizacionais (liderança e influência social) e com os órgãos governamentais (participação em projetos sociais governamentais).

Tal constatação é coerente com o princípio estabelecido pelo Ethos (2007) da relação ética e transparente com a sociedade e da orientação para metas empresariais que privilegiem o desenvolvimento sustentável. Ademais, espera-se que a empresa se comprometa com normas e com padrões, bem como adote um comportamento esperado pelos quais se relaciona (BORINELLI; VENTURA, 2004).

A Tabela2 contém a lista de ações que caracterizam a gestão ambiental corporativa. As três ações mais relevantes confirmam a afirmação de Viterbo Jr (1998) de que comprometer-

REAd | Porto Alegre - Edição 86 - No 2 - Maio / Agosto 2017 - p. 31 - 57 
se não significa estar atento ao meio ambiente em si, mas sim à melhoria dos produtos, dos processos e dos serviços, a fim de torná-los menos agressivos.

O primeiro item trata do cumprimento da legislação e da regulamentação ambiental, tais como licenciamento e elaboração do relatório de impacto ambiental - o qual contém medidas mitigatórias, de monitoramento e compensatórias.

O segundo item observa o compromisso permanente para com a redução dos impactos causados pelo produto, desde a extração da matéria-prima até o descarte da embalagem, relacionando-se ainda com o terceiro, que trata da melhoria contínua nos processos e na tecnologia nos produtos a fim de torná-los ambientalmente eficientes.

Tabela2-Escores Subjetivos para as Ações de Gestão Ambiental Corporativa

\begin{tabular}{|c|c|c|c|c|c|c|c|c|c|c|c|c|c|c|c|}
\hline Indicador & $\mathbf{A}$ & B & $\mathbf{C}$ & $\mathbf{D}$ & $\mathbf{E}$ & $\mathbf{F}$ & $\mathbf{G}$ & $\mathbf{H}$ & I & $\mathbf{J}$ & $\mathbf{K}$ & $\mathbf{L}$ & $\mathbf{M}$ & $\mathbf{N}$ & $\mathbf{O}$ \\
\hline Cumprimento da legislação ambiental & 3 & 3 & 1 & 3 & 3 & 3 & 3 & 2 & 3 & 2 & 3 & 3 & 3 & 2 & 3 \\
\hline Gestão do ciclo de vida dos produtos & 2 & 2 & 1 & 1 & 1 & & 3 & 3 & 2 & 3 & 3 & 3 & 2 & 3 & 3 \\
\hline Melhoria ambiental em processos & 3 & & & & 2 & 3 & 2 & 3 & 3 & & 2 & 2 & 2 & & 2 \\
\hline Seriedade com impactos ambientais & 1 & 3 & & 3 & & 2 & 2 & 2 & 2 & 2 & 2 & & 3 & & 2 \\
\hline Conscientização ambiental à comunidade & 2 & 1 & & 2 & 1 & 2 & 1 & 2 & 1 & 3 & 1 & & & 1 & 2 \\
\hline Controla o risco de acidentes ambientais & 1 & 2 & 2 & & 2 & & 2 & 2 & & & 2 & 1 & 1 & 3 & \\
\hline Busca reduzir o consumo de água & & 1 & 3 & 2 & 2 & 1 & 1 & & 1 & 2 & & 2 & 1 & 1 & 1 \\
\hline Conscientização ambiental empregados & 2 & 1 & 1 & 1 & 1 & 2 & 1 & 1 & & & 1 & 2 & 2 & 2 & \\
\hline Ciência dos danos potenciais de produtos & 1 & 2 & 1 & 1 & & 2 & & 1 & 2 & & 2 & 1 & & & 2 \\
\hline Busca reduzir o consumo de energia & & 1 & 3 & & 2 & 1 & & & 1 & 2 & & 2 & & 1 & 1 \\
\hline Investe e busca reduzir poluentes & 2 & & & 2 & & & 2 & & & 1 & 1 & 1 & 2 & 2 & 1 \\
\hline Investe e promove redução de resíduos & 1 & 2 & 2 & 1 & & 1 & & & 2 & & 1 & & 1 & & 1 \\
\hline Reduz o consumo de matéria-prima & & & & & 3 & 1 & 1 & & 1 & 1 & & & & 2 & \\
\hline Investe promove reutilização de resíduos & & & 2 & 2 & 1 & & & 1 & & 1 & & 1 & 1 & 1 & \\
\hline Investe e promove reciclagem de resíduos & & & 2 & & & & & 1 & & 1 & & & & & \\
\hline
\end{tabular}

A lista da Tabela3 demonstra que, dentre as cinco ações consideradas mais relevantes para a explicação da face de Marketing ambiental, três têm vínculo com a iniciativa da empresa em selecionar fornecedores, em investir em projetos e em promover inovações que apresentem preocupação com os impactos provocados sobre o meio ambiente. A escolha dessas ações por parte dos especialistas confirma as posições de Peattie e Charter (2005) e de Polonski (2001) de que o compromisso ambiental a montante - ou seja, de que os fornecedores são corresponsáveis pelos impactos causados - denota a visão integrada do processo.

Pode se observar a importância dada à relação com as partes interessadasno processo produtivo eou com a prestação de serviços, uma vez que se direcionam aosfornecedores (critérios de seleção e de avaliação de fornecedores, e análise da cadeiade suprimentos), aos concorrentes (relações com a concorrência), aos clientes(excelência no atendimento) e à 
comunidade (investimento em proteção ambiental,minimização dos impactos ambientais e confiabilidade).

Cabe ressaltar que, a atributos relacionados aos critérios de seleção edeavaliação dos fornecedores e à análise da cadeia de suprimentos, também sevinculam a dimensão da análise do ciclo de vida dos produtos eou dos serviçosprestados pelas organizações.

Outro ponto importante está relacionado ao processo de educação edeconscientização do consumidor e à política de comunicação comercial implementadapelas organizações. Isso porque estão relacionados tanto à conscientização em relação aosdesafios ambientais decorrentes da atividade humana, como à consciência daorganização quanto ao seu papel na formação de valores e padrões de consumo.

Tabela3 - Escores Subjetivos para as Ações de Marketing Ambiental

\begin{tabular}{|c|c|c|c|c|c|c|c|c|c|c|c|c|c|c|c|}
\hline Indicador & $\mathbf{A}$ & B & $\mathbf{C}$ & $\mathbf{D}$ & $\mathbf{E}$ & $\mathbf{F}$ & $\mathbf{G}$ & $\mathbf{H}$ & I & $\mathbf{J}$ & $\mathbf{K}$ & $\mathbf{L}$ & $\mathbf{M}$ & $\mathbf{N}$ & $\mathbf{O}$ \\
\hline Fornecedores possuem respeito ambiental & 3 & 1 & 2 & 3 & 2 & 2 & 2 & 2 & 3 & 2 & 3 & 2 & 3 & & 3 \\
\hline Investe em projetos c/ proteção ambiental & 3 & 2 & & 2 & & 1 & 2 & 2 & 2 & 3 & 2 & & 3 & 3 & 1 \\
\hline Combate práticas desleais concorrência & & & 3 & 1 & 3 & & 3 & & 2 & & 3 & 3 & 1 & & 3 \\
\hline Atendimento com diálogo e engajamento & & & 3 & & 3 & 2 & 2 & 3 & 3 & 1 & 1 & 2 & & & 2 \\
\hline Inovações p/ reduzir impactos ambientais & 2 & 3 & & 3 & & & 2 & 1 & & 2 & 2 & 2 & & 3 & 2 \\
\hline Consciência sobre formação de valores & 1 & & 2 & & & 3 & 3 & 2 & 2 & 2 & 2 & & 2 & & 1 \\
\hline Possui produtos seguros para o ambiente & 2 & 3 & 1 & 1 & 1 & 2 & 1 & 2 & 1 & 3 & & & 1 & 1 & \\
\hline Visão ambiental da cadeia suprimentos & 2 & 2 & & & 1 & 3 & & 1 & 2 & & 1 & 2 & 1 & 2 & 2 \\
\hline Educa consumidor para causa ambiental & 1 & 2 & 2 & 2 & 1 & 1 & & 3 & & 1 & 1 & & 2 & 2 & 1 \\
\hline Oferece produtos com maior durabilidade & & & 1 & & 2 & 2 & 1 & 1 & 1 & & & 1 & & 2 & \\
\hline Apoia a educação dos fornecedores & 2 & 1 & 2 & 2 & & & & 1 & & & 1 & 1 & & & 2 \\
\hline Indicam aspectos ambientais nos rótulos & & 1 & & 1 & 2 & & & & & 1 & 2 & 1 & 2 & 1 & \\
\hline Produtos com facilidade de reciclagem & & & 1 & 1 & & 1 & 1 & & 1 & 2 & & 1 & & 2 & 1 \\
\hline Destinação final adequada aos resíduos & 1 & 2 & 1 & & 1 & & 1 & & 1 & 1 & & & 2 & 1 & \\
\hline Evita criar passivos ambientais & 1 & 1 & & 2 & 2 & 1 & & & & & & & 1 & 1 & \\
\hline
\end{tabular}

Fonte: Elaboração própria

A GSI ilustrada na Pirâmide da Sustentabilidade Empresarial (ver Figura 1) resume o resultado das ações identificadas pelos especialistas como de alta prioridade para que um projeto ou um produto apresente coerência no comprometimento com suas três faces.

A RSC está vinculada à ética e à transparência esperadas nas alterações nas condições de bem-estar ligadas às dimensões sociais das atitudes produtivas, da qualidade de vida da sociedade, e da estreita relação entre a empresa e o seu ambiente (DONAIRE, 1999). 


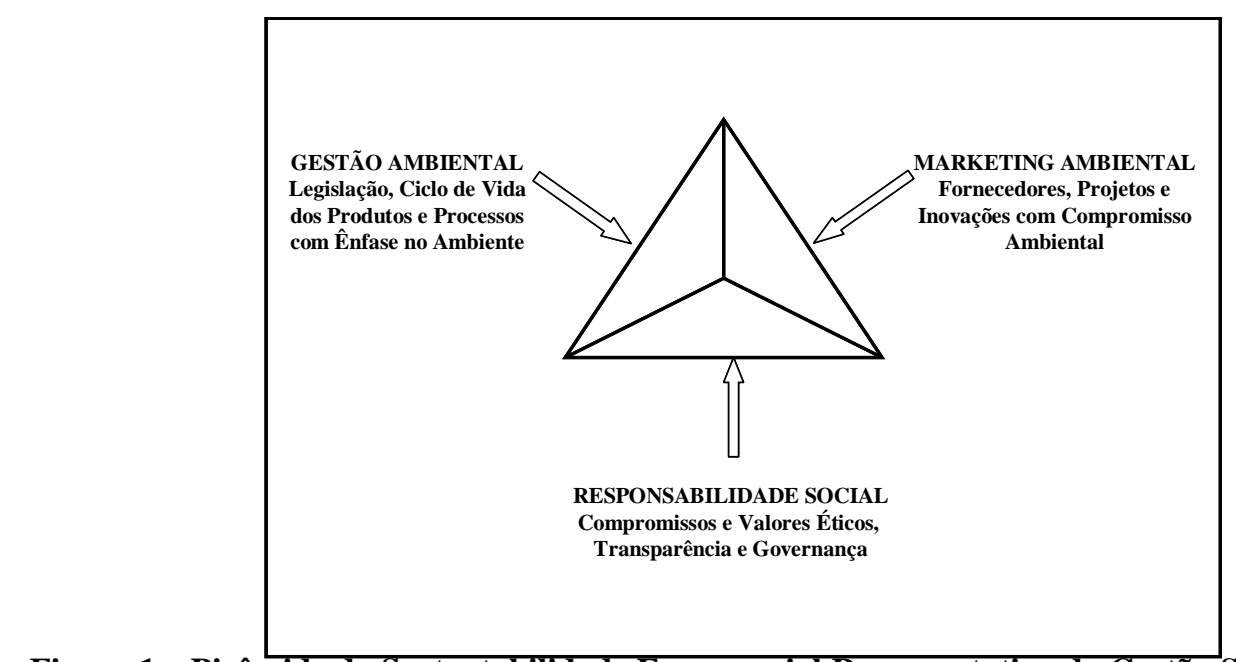

Figura 1 - Pirâmide da Sustentabilidade Empresarial Representativa da Gestão Sustentável Integrada (GSI)

Fonte: Elaboração própria

Para Carrol (1999), ocorre a expectativa ditada pela sociedade de que as empresas atendam às dimensões econômicas, legais, éticas e sociais. Uma organização somente atua de forma ética quando trilha a conquista de suas metas, respeitando os valores e os direitos da sociedade na qual está inserida (DUARTE; DIAS, 1986).

Os estudos de Brown (2005), de Peattie e Charter (2005), de Porter e Van der Linde (1995) e de Ottman (1993) esclarecem que a gestão ambiental interage com a sociedade por meio de uma nova relação de consumo, promovendo ações ambientais de preservação, de conservação e de monitoramento, incentivando o maior "esverdeamento" das organizações, além de representar um ganho de brandequity.

Ottman (1993) e Polonsky (2001) ressaltam os esforços das organizações em satisfazer as expectativas dos consumidores por produtos que determinem menores impactos ambientais ao longo do seu ciclo de vida, que compreende as fases de matéria-prima, produção, embalagem, consumo e descarte. Acima de tudo, deve-se buscar o atendimento aos requisitos ambientais estabelecidos pelas agências estaduais e pelos órgãos federais, pressupostos para a obtenção e para a manutenção da licença ambiental de operação, constituindo-se em importante mecanismo formal de prevenção.

Quanto à face do Marketing ambiental, os conceitos seguem por uma vertente que busca o alinhamento dos agentes do processo de agregação de valor aos princípios da responsabilidade ambiental. A inclusão do dilema ambiental nas organizações coincide com a afirmação de Smith (2003) de que a conscientização dos consumidores tende a crescer, como consequência da maior disseminação da informação. $\mathrm{O}$ consumidor procurará informar-se 
sobre as dimensões do sacrifício social representado a partir da produção de certos bens e serviços, responsabilizando aquelas empresas que estejam prejudicando a sociedade.

A inclusão da preocupação com o meio ambiente na cadeia de agregação de valor é justificável após a percepção de que se trata de um recurso estratégico na busca por diferenciação do produto. Essa abordagem confirma a expectativa de que a conservação do meio ambiente será o fator que mais influenciará nas decisões de produção e nas políticas de Marketing, fator crítico que definirá sobre a permanência de uma empresa no mercado.

\section{CONSIDERAÇÕES FINAIS}

Um dos pontos mais importantes do conceito de gestão ambiental colocado por Tashizawa (2002) é a incorporação das inovações, tanto para os processos industriais (por meio do uso de tecnologias limpas e do desenvolvimento da ecoeficiência) como também das inovações dos produtos, trazendo ao mercado ecoprodutos ou produtos que contenham um maior envolvimento ambiental.

O fato de as empresas estarem adaptadas ao conceito da GSI implica (a) assumir compromissos e valores éticos e respeitar as leis; (b) dar transparência às ações empresariais e adotar a governança corporativa; e (c) educar fornecedores e utilizar de criatividade e de bom senso na gestão de projetos e de inovações comprometidas com o meio ambiente.

São determinantes, para o desenvolvimento de cenários que suportem as estratégias organizacionais, uma análise da conjuntura e um diagnóstico adequado que considerem as múltiplas relações e a complexidade intrínseca das questões econômicas, ambientais e sociais, assim como o entendimento das oportunidades de negócios abertos por consumidores mais conscientes, e a compreensão dos novos desafios impostos às empresas.

Qualquer mudança implica determinado período de amadurecimento e de aceitação das novas ideias e realidades, que podem desestabilizar e ameaçar as estruturas existentes. Perspectivas dessa envergadura carecem de esforços em direção tanto do desenvolvimento quanto da aplicação de novas técnicas e conceitos.

Inovações tecnológicas, novos hábitos e valores tiveram papel preponderante para a construção de novos paradigmas, pois, em diversas oportunidades, provocaram, aceleraram e permitiram que se chegasse a uma convergência de interesses entre a produção econômica, o desenvolvimento social e a conservação ambiental.

A gestão apoiada no esquema conceitual GSI tem, por premissa, o relacionamento ético e transparente da organização com as partes interessadas em suas atividades. Busca 
desenvolver a sociedade, preservando os recursos naturais e culturais por meio de uma gestão participativa que respeita a diversidade e que reduz desigualdades, com a concomitante tarefa de satisfazer as necessidades dos clientes de modo sustentável e lucrativo para as organizações.

A sensibilidade organizacional deve transformar a economia e as questões sociais e ambientais em parceiras de uma nova concepção produtiva. Isso garante a capacidade de suporte do planeta, elimina as desigualdades sociais, e aumenta a competitividade das organizações. Esse é o desafio ora apresentado para os gestores organizacionais. Enfim, o conjunto de ideias discutidas no presente trabalho conduz ao pensamento crítico com vistas a contribuir para a construção de uma sociedade mais justa, democrática e ambientalmente mais responsável.

A academia poderá utilizar a proposta do GSI em suas três dimensões responsabilidade social corporativa, gestão ambiental e marketing ambiental - como uma estrutura de referência para apoiar o desenvolvimento de modelos em estudos de caso, assim como no aprimoramento de estudos de impactos socioambientais em diversos contextos.

A aplicação da metodologia no ambiente empresarial é de amplo espectro, sendo particularmente recomendada na avaliação multicritério da viabilidade de projetos e em sua seleção por critérios outros que não aqueles meramente econômicos. Por apresentar critérios pré-estabelecidos, apresenta facilidade de especificação. Ademais, a empresa poderá melhor avaliar suas ações empresariais no escopo do GSI e, assim, embasar com maior transparência as ações tomadas e explicitadas na elaboração do Balanço Socioambiental.

Como extensão da presente pesquisa, um ensaio empírico foi efetuado no município fluminense de Cabo Frio com o objetivo de validar a estrutura proposta para a GSI. Na ocasião, foram comparadas três concessionárias públicas responsáveis (1) pela distribuição de energia elétrica, (2) pela distribuição de água, pela coleta de esgotos e pelo saneamento ambiental, e (3) pelo transporte rodoviário urbano de passageiros.

A segunda etapa deste ensaio consistirá na análise a ser efetuada sobre uma amostra maior, cujos resultados serão futuramente apresentados à academia para críticas e sugestões.

\section{REFERÊNCIAS}

ACSELRAD, H. Novas Articulações em Prol da Justiça Ambiental.Democracia Viva, Rio de Janeiro, v.27, p. 42-47, Jul. 2005. 
AĞAN, Y. et al.The relationships between corporate social responsibility, environmental supplier development, and firm performance.Journal of Cleaner Production, Amsterdam, v.112, n.3, p. 1872-1881, 2016.

AHI, P.; SEARCY, C. An analysis of metrics used to measure performance in green and sustainable supply chains. JournalofCleanerProduction, Amsterdam, v.86, n.1, p. 360-377, 2015.

ALMEIDA, F. O Bom Negócio da Sustentabilidade. Rio de Janeiro: Nova Fronteira, 2002.

ALVES, E.A. Dimensões da Responsabilidade Social da Empresa: uma abordagem desenvolvida a partir da visão de Bowen. Revista de Administração,[s.1.], v.38, n.1, p. 37 45, jan./mar. 2003.

BARBIERI, J.C. Gestão Ambiental Corporativa: conceitos, modelos e instrumentos. São Paulo: Saraiva, 2004.

BESSERMAN, S. A Lacuna das Informações Ambientais. In: TRIGUEIRO, A. (Coord.). Meio Ambiente no Século 21: 21 especialistas falam da questão ambiental nas suas áreas de conhecimento. 4. ed. Campinas: Armazém do Ipê (Autores Associados), 2005. p. 91 - 105.

BORINELLI, B.; VENTURA, E.C.F. Ética, Valores e Cultura: especificidades do conceito de responsabilidade corporativa. In: ASHLEY, P.A. et al. (Coord.). Ética e Responsabilidade Social nos Negócios. São Paulo: Saraiva, 2004. p.48-61.

BORGER, F.G. Responsabilidade Social: efeitos da atuação social na dinâmica empresarial. 2001. 210 f. Tese (Doutorado em Administração de Empresas) - FEA/USP, São Paulo, 2001.

BRENDE, B. Introdução. In: IGLESIAS, E. Estado do Mundo, 2004: estado do consumo e o consumo sustentável. Salvador:Uma, 2004.

BROWN, S. Marketing pós-moderno: vale tudo! In: BAKER, M. J. (Org). Administração de marketing - conceitos revistos e atualizados. Rio de Janeiro: Elsevier, 2005.p.13-23.

BUARQUE, S. Construindo o Desenvolvimento Local Sustentável. 2. Ed. Rio de Janeiro:Garamond, 2004.

BURKE, L.; LOGDON, J.M. How corporate social responsibility pays off. Long Range Planning, Amsterdam, v.29, n. 4, p. 495-502, 1996.

CMIMAD. NossoFuturoComum. Rio de Janeiro:FGV, 1991.

COSTA, M. M.; COHEN, I.; SCHAEFFER, R. Social Features of Energy Production and Use in Brazil: goals for a sustainable energy future. Natural ResourcesForum,Hoboken, n. 31, p. 11-20. 2007.

DIAZ, C.A.P.; PIRES, S.R.I. Produção Mais Limpa: integrando meio ambiente e produtividade. Revista de Administração CREUPI, [s.1.], v.5, n. 9, p. 51-57, 2005. 
DIXON-FOWLER, H.R. et al. Beyond "Does it Pay to be Green?" A Meta-Analysis of Moderators of the CEP-CFP Relationship. Journal of Business Ethics, New York, v.112, n.2, p. 353-366, 2013.

DONAIRE, D. GestãoAmbientalnaEmpresa.2. Ed. São Paulo:Atlas, 1999.

DUARTE, G.D.; DIAS, J.M. Responsabilidade Social: a empresa hoje. Rio de Janeiro: Livros Técnicos e Científicos, 1985.

ETHOS. Indicadores de Responsabilidade Social Empresarial: 2006. São Paulo: Ethos, 2006.

ETHOS. Perguntas Frequentes. Disponível em: <http:// www.uniethos.Org.br>.Acessoem: 02 mar. 2007.

FLAMMER, C. Does Corporate Social Responsibility Lead to Superior Financial Performance? A Regression Discontinuity Approach.Management Science, Catonsville, v.61, n.11, 2015.

FLAVIN, C. Prefácio.In: IGLESIAS, E.Estado do Mundo, 2004: estado do consumo e o consumo sustentável. Salvador:Uma, 2004.

GOBBI, B.C. Gestão Ambiental como Prática Social: uma análise dos sentidos da interação organização e meio ambiente. 126 f. 2005. Dissertação (Mestrado em Administração) Programa de Pós-Graduação em Administração, Universidade de Lavras, Minas Gerais,2005.

GONÇALVES, B.S. (Coord.). Responsabilidade Social Corporativa nos Processos Gerenciais e nas Cadeias de Valor. São Paulo:Instituto Ethos, 2006.

GUERREIRO, C. Empresas Associam suas Marcas a Boas Práticas. São Paulo:Gazeta Mercantil. 21 ago. 2007.

HOLME, R.; WATTS, P. Responsabilidade Social Corporativa(RSC): bom senso aliado a bons negócios. São Paulo:WBCSD, 2000.

IPCC.Climate Change 2007: the physical science basis. $10^{\text {th }}$ Session of Working Group I of the Intergovernmental Panel for Climate Change, Paris, Feb-2007.

JABBOUR, C.J.C.; SANTOS, F.C.A. Integrando Gestão de Recursos Humanos e Gestão Ambiental na Empresa. In: ENCONTRO DA ANPAD,30., 2006,

Salvador.Anais...Salvador:ANPAD, 2006.

JACKSON, T.; MICHAELIS, L. Policies for Sustainable Consumption. Report for the Sustainable Development Commission. Surrey: Center for Environmental Strategy, 2003.

JENKINS, H.; YAKOVLEVA, N. Corporate social responsibility in the mining industry: Exploring trends in social and environmental disclosure. Journal of Cleaner Production, Amsterdam, v.14, n. 3-4, p. 271-284, 2006. 
KATSIKEAS, C.S.; LEONIDOU, C.N.; ZERITI, A. Eco-friendly product development strategy: antecedents, outcomes, and contingent effects. Journal of the Academy of Marketing Science (online), p.1-15, 2016. DOI: 10.1007/s11747-015-0470-5.

LEFF, E. Racionalidade Ambiental: a reapropriação social da natureza. Rio de Janeiro: Civilização Brasileira, 2006.

LEONIDOU, L.C. et al. Internal Drivers and Performance Consequences of Small Firm Green Business Strategy: The Moderating Role of External Forces. Journal of Business (online), p.1-22, 2015. DOI: 10.1007/s10551-015-2670-9.

MARSHALL JÚNIOR, I. et al.(Coord.). Gestão da Qualidade. Rio de Janeiro:FGV, 2003.

MATAR, H. Consumo Consciente e Responsabilidade Social. Diálogos Akatu,São Paulo, v. 1, n. 1, p. 3-10, 2002.

MCWILLIAMS, A.; SIEGEL, D.S.; WRIGHT, P.M. Corporate Social Responsibility: Strategic Implications. Journalof Management Studies, Hoboken, v.43, n.1, p.1-18, 2006,

MMA. Ministério do Meio Ambiente. Disponível em:<www.mma.gov.br>. Acesso em: 19 mar. 2008.

NASCIMENTO, F. Gestão Socioambiental Estratégica: a percepção de executivos de pequenas e médias empresas americanas. In: ENCONTRO DA ANPAD, 29., 2005, Brasília. Anais... Brasília:ANPAD, 2005. CD-ROM.

NBR ISO 14001. Sistemas de Gestão Ambiental: especificações e diretrizes para uso. Rio de Janeiro:ABNT, 1996.

NBR ISO 14004. Sistemas de gestão ambiental: diretrizes gerais sobre princípios, sistemas e técnicas de apoio. Rio de Janeiro: ABNT, 1996.

ONU. Conferência das Nações Unidas sobre Meio Ambiente e Desenvolvimento. Rio de Janeiro: ONU, 1992. In: SENADO FEDERAL. Agenda 21. 3. ed.Brasília:Senado Federal, 2001.

OTTMAN, J.A. Marketing Verde: desafios e oportunidades para a nova era do marketing. São Paulo:Makron, 1993.

PAULRAJ, A.; CHEN, I.J.; BLOME, C. Motives and Performance Outcomes of Sustainable Supply Chain Management Practices: A Multi-theoretical Perspective. Journal of Business Ethics (online), p.1-20, 2015. DOI: 10.1007/s10551-015-2857-0.

PEATTIE, K.; CHARTER, M. Marketing Verde.In: BAZER, M. J. (Org.).Administração de Marketing: conceitos revistos e atualizados. Rio de Janeiro:Elsevier, 2005.p.517-537.

PINHEIRO, C. S.; CÍPOLA, F. C.; PEREIRA, A. N.; COSTA, S. R. R. Responsabilidade Social na gestão para excelência como agregadora de atributo mercadológico: o caso da Natura. In: SIMPÓSIO DE GESTÃO EM ESTRATÉGIA E NEGÓCIOS, 2006, Resende. Anais... Resende: UFRRJ, 2006.CD-ROM. 
POLONSKY, M.J. An Introduction to Green Marketing.University of Newcastle, Australia, 2001.

PORTER, M. E.; VANDER LINDE, C. Green and Competitive: ending the stalemate. Harvard Business Review, Brighton, p. 119 - 124, Sept./Oct. 1995.

RIBAS, J.; SMITH, S. O Marketing AmbientalRecompensa?Colóquio Internacional sobre Poder Local, 10., 2006, Salvador. Anais...Salvador:CIAGS, 2006. CD-ROM.

ROESCH, S. M. A. Projetos de estágio e de pesquisa em administração: guia para estágios, trabalhos de conclusão, dissertações e estudo de caso. 2. ed. São Paulo: Atlas, 1999.

SMITH, N.C. Corporate Social Responsability: whether or how? California Management Review, Thousand Oaks, v.45, n. 4, p. 52-76, 2003.

URSINI, T.R.; BRUNO, G.O. A Gestão para a Responsabilidade Social e oDesenvolvimento Sustentável. Revista da Fundação de Apoio à Tecnologia,São Paulo, p.31-34, 2005.

VITERBO JÚNIOR, E. Sistema Integrado de Gestão Ambiental. 2.ed. Aquariana: São Paulo, 1998.

YOUNG, R. Gestão da Responsabilidade Social e do Desenvolvimento Sustentável. 2005. Disponível em:<http:// www.uniethos.Org.br $>$.Acesso em: 06 abr. 2015.

WARTICK, S.; COCHRAN, P.The Evolution of the Corporate Social Performance Model.Academy of Management Review, Briarcliff Manor, v.10, p.758-769, 1985.

WBCSD -The World Business Council for Sustainable Development. Corporate Social Responsibility: making good business sense. Genebra: WBCSD, 2000.

WCED.Our Common Future.Brundtland Report. Berna: World Commission on Environment and Development, 1987.

\footnotetext{
iÓrgão intergovernamental estabelecido em 1988 pela Organização Meteorológica Mundial (OMM) e pelo Programa das Nações Unidas para o Meio Ambiente (PNUMA) e aberto para seus países-membros, visando a fornecer informações científicas, técnicas e socioeconômicas relevantes para o entendimento das mudanças climáticas.

${ }^{i i}$ Um dos principais documentos resultantes da Conferência das Nações Unidas sobre Meio Ambiente e Desenvolvimento (CNUMAD), no Rio de Janeiro, em 1992, estabeleceu a importância de cada país a se comprometer a refletir, global e localmente, sobre a forma pela qual governos, empresas, organizações nãogovernamentais e todos os setores da sociedade poderiam cooperar no estudo de soluções para os problemas socioambientais.

iii Documento elaborado durante a Conferência das Nações Unidas sobre Meio Ambiente e Desenvolvimento (CNUMAD), no Rio de Janeiro, em 1992, com o objetivo de estabelecer uma nova e justa parceria global mediante a criação de novos níveis de cooperação entre os Estados, a sociedade e os indivíduos, trabalhando pela criação de acordos internacionais que respeitem os interesses de todos e protejam a integridade do sistema global de meio ambiente e desenvolvimento. Ao todo, são 27 princípios do documento, entre eles o do "desenvolvimento sustentável", o da "preocupação" e o do "poluidor pagador".

${ }^{\text {iv }}$ Documento resultante da Cúpula Mundial sobre Desenvolvimento Sustentável, realizada em Johannesburgo em setembro de 2002
} 
${ }^{v}$ O Instituto Ethos de Empresas e Responsabilidade Social é uma organização sem fins lucrativos, caracterizada como Oscip (organização da sociedade civil de interesse público). Sua missão é mobilizar, sensibilizar e ajudar as empresas a gerir seus negócios de forma socialmente responsável, tornando-as parceiras na construção de uma sociedade justa e sustentável.

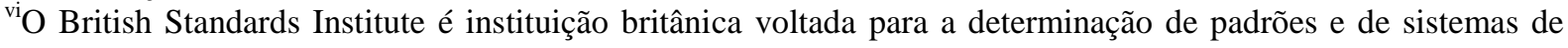
gerenciamento de melhorias dos negócios

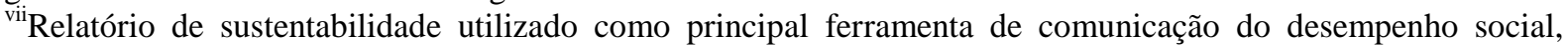
ambiental e econômico das organizações, e cujo modelo é atualmente o mais completo e mundialmente difundido, tendo em vista que a GRI foi criada com o objetivo de elevar as práticas destes relatórios a nível de qualidade equivalente ao dos relatórios financeiros.

viii Triple BottomLine (ou People, Planet, Profit) são os resultados de uma empresa medidos em termos sociais, ambientais e econômicos. São apresentados nos relatórios corporativos das empresas comprometidas com o desenvolvimento sustentável. Por enquanto, são medições de caráter voluntário.

${ }^{\mathrm{ix}}$ Documento elaborado pela Comissão Mundial sobre Meio Ambiente e Desenvolvimento, intitulado Nosso Futuro Comum, publicado em 1987, no qual desenvolvimento sustentável é concebido como "o desenvolvimento que satisfaz as necessidades presentes, sem comprometer a capacidade das gerações futuras de suprir suas próprias necessidades".

${ }^{\mathrm{x}}$ Terceira conferência mundial promovida pela ONU para discutir os desafios ambientais do planeta.

${ }^{x i}$ Associação de cerca de 200 empresas voltadas exclusivamente para o desenvolvimento sustentável dos negócios.

xii Normas que determinam diretrizes para garantir que determinada empresa pública ou privada pratique a gestão ambiental, conhecidas pelo Sistema de Gestão Ambiental (SGA)definido pela InternationalOrganization for Standardization (ISO). 